\title{
Abelhas Jataís e Educação Ambiental: Uma Experiência Interdisciplinar na Formação de Professores em Ciências Agrárias
}

\author{
Caio de Oliveira Loconte ${ }^{1}$; Júlia Barbosa de Paiva ${ }^{1 ;}$ Vânia Galinda Massabni²; Rosebelly \\ Nunes Marques ${ }^{2}$ \\ ${ }^{1}$ Graduandos em Engenharia Florestal e Licenciatura em Ciências Agrárias na Escola Superior de Agricultura \\ Luiz de Queiroz da Universidade de São Paulo \\ ${ }^{2}$ Departamento de Economia, Administração e Sociologia - LES/Esalq/USP
}

* Autores para correspondência: caioloconte70@yahoo.com.br, juliabarbosadepaiva@yahoo.com.br, massabni@usp.br, rosebelly.esalq@usp.br

\section{RESUMO}

O ensino deve estimular a curiosidade, a exploração e o questionamento das crianças em relação ao mundo físico, social e à natureza. Esse estímulo pode decorrer de ações que desmistifiquem abelhas, valorizando experiências da criança com o inseto no ambiente, em uma perspectiva de educação ambiental. Nesse sentido, o presente estudo surgiu da interação de três disciplinas da Licenciatura em Ciências Agrárias da Escola Superior de Agricultura "Luiz de Queiroz", objetivando que os licenciandos idealizassem, elaborassem e desenvolvessem o estágio com o tema "abelhas nativas e polinização" na educação infantil. O trabalho envolveu a definição de uma metodologia de ensino, confecção de instrumento didático (caixa-ninho de abelhas), intervenções pedagógicas com atividades práticas, com ações junto aos pais e professores da escola. Destacam-se três aspectos nos quais este trabalho contribuiu: a) para a experiência dos licenciandos como docentes, ao projetar e conduzir a intervenção pedagógica incluindo um instrumento de ensino e sua confecção; b) para o diálogo entre as disciplinas da Licenciatura em uma proposta de estágio integrado, em que este atuou como articulador; c) para a reflexão sobre a aprendizagem das crianças quanto ao tema escolhido, as abelhas jataís e sua forma de vida, utilizando os desenhos delas. Os licenciandos constantemente se questionaram, discutiram e solicitaram orientações, de modo a relacionar teoria e prática e aprendizagens das disciplinas pedagógicas e específicas, como requer um processo complexo, mas que pode ser fascinante, de tornar-se professor.

Palavras-Chave: Educação Ambiental; Metodologia e Instrumentação no Ensino; Licenciatura em Ciências Agrárias.

\begin{abstract}
The process of education should stimulate children's curiosity, exploration and questioning about the physical, social and natural world. The stimulation can be enhance by demystification of the bees valuing child experience whit insects in environment, from a environmental education perspective. In this sense, the present study arose from the interaction of three disciplines of the Teacher Training in Agricultural Sciences of the "Luiz de Queiroz" College of Agriculture, aiming that the education-students idealize, elaborate and execute a pedagogical activity with the theme "native bees and pollination". The work involved the definition of a teaching methodology, the creation of a didactic tool (hive-box of bees), pedagogical interventions with practical activities and elaboration of project's dissemination material. The evaluation of the education-students' learning was done through reports, while the effectiveness of the methodology was through drawings made by the children (before and after the interventions). As a results, there are three points of contributions: a) to student experience like teachers, to elaborate e conduct the pedagogical intervention, including a teaching resource and its production; $b$ ) to the dialog concern in disciplines of a teacher training is a proposal of integrated practicum and this practicum has a articulator paper; c) to reflection about children learning in theme Jataís bees and its way of life, using their design. Graduates have constantly questioned, discussed, and asked for guidance in order to relate theory and practice and learning from specific and pedagogical disciplines, as it requires a complex but fascinating process of becoming a teacher.
\end{abstract}

Keywords: Environmental Education; Methodology and Instrumentation of Teaching; Teacher Training in Agrarian Sciences. 


\section{Introdução}

A Formação Docente na Graduação: a Licenciatura em Ciências Agrárias

Conforme Flores (2006), tornar-se professor constitui um processo longo e complexo que implica a (trans)formação da identidade profissional, sendo compromisso dos cursos de formação de professores valorizar a construção dessa identidade. No contexto de cursos de graduação que visam a formar professores, as Licenciaturas, incluindo a Pedagogia e os estágios supervisionados, são fundamentais para esse processo, porque oferecem oportunidade para o graduando vivenciar o cotidiano escolar, colaborando com seu desenvolvimento profissional docente.

Ao ensinar é necessário mobilizar grande variedade de saberes (TARDIF, 2002), em um processo pessoal que envolve a reflexão sobre como articular e dimensionar os conhecimentos pedagógicos e os da área específica em situações da prática docente. A relevância da reflexão na formação docente é abordada na perspectiva do professor como pesquisador e profissional reflexivo, em contraposição a uma visão do professor como técnico, para quem bastaria saber "aplicar" técnicas relacionadas ao "como ensinar" (PIMENTA, 2005). Segundo Massabni (2011), ser professor vai muito além de uma atividade burocrática, para a qual bastaria saber qual a técnica pedagógica mais adequada a uma situação de ensino, saber utilizar o livro didático ou outros recursos pedagógicos, ou ainda dominar o conhecimento científico atual.

$\mathrm{Na}$ universidade, tradicionalmente na organização dos cursos, são selecionados conteúdos para cada conjunto de disciplinas sem considerar a complexidade do contexto de trabalho. A fragmentação e o distanciamento entre teoria e prática também são alvo de críticas nas Licenciaturas (DIAS-DA-SILVA \& MUZZETI, 2006). As disciplinas costumam ser estanques, e a fragmentação deixa ao graduando entrever a prática a partir de um "mosaico" que faz com o conhecimento elaborado em cada disciplina. Segundo Cunha (2008), um dos marcos de inovação das práticas pedagógicas universitárias é a ruptura desse formato, com reorganização da relação entre teoria e prática por meio das dúvidas e problematizações da realidade que conferem sentido à teoria pelo estudante. Assim, o desenvolvimento do estágio como uma atitude investigativa da prática é uma forma de reorientar a formação docente (PIMENTA, 2005) e enfrentar a falta de vínculo entre teoria e prática.

Considerando a perspectiva formativa anunciada, o presente artigo busca relatar e analisar uma experiência de integração entre disciplinas que possuem estágio supervisionado no curso de Licenciatura em Ciências Agrárias da Escola Superior de Agricultura Luiz de Queiróz, Esalq/ USP, em Piracicaba, São Paulo. Possibilitou-se que licenciandos vivenciassem a prática docente nos estágios exigidos em três disciplinas pedagógicas, conforme a perspectiva e a especificidade de cada disciplina em questão. Além de focalizar aspectos pedagógicos diferentes nessa prática, buscou-se a articulação aos saberes da área específica de Ciências Agrárias, o que se constituiu em novidade e desafio aos docentes e licenciandos.

Na Universidade de São Paulo, os estágios estão atrelados às disciplinas, conforme o Programa de Formação de Professores da USP - PFP (USP, 2004), nas quais a relação teoria e prática possa estar em discussão e presente nos projetos político-pedagógicos (PPP) dos cursos. Os estágios supervisionados devem integrar, obrigatoriamente, o currículo dos cursos de formação de professores, atendendo as horas da legislação em vigor, que também prevê horas a serem cumpridas nos estágios.

A Licenciatura em Giências Agrárias é oferecida na Esalq/USP para os graduandos em Engenharia Agronômica e Florestal, que optam por cursar disciplinas pedagógicas em paralelo ao seu curso de ingresso na universidade. Visa a formar professores para atuar em cursos técnicos na educação profissional nas áreas de agropecuária, meio ambiente e outras, conforme o PPP do curso (ESALQ 2015). A criação de abelhas é e pode ser uma prática relacionada à agropecuária 
e, dependendo de como é abordada, à área agroecológica e suas relações com a biologia das abelhas e ecologia e constituiu-se em tema do projeto de estágio.

O presente trabalho teve como objetivo oferecer aos licenciandos o desafio de elaborar e vivenciar uma metodologia de ensino, que deveria utilizar uma ferramenta instrumental desenvolvida pelos próprios graduandos, adequada aos estudantes da educação infantil (crianças de três a cinco anos) do Centro de Convivência Infantil "Ermelinda Ottoni de Souza Queiroz" (CCIn), pertencente à Prefeitura do Campus "Luiz de Queiroz"/USP. Participaram dois graduandos da Engenharia Florestal que cursavam a Licenciatura em Ciências Agrárias, enquanto os demais estudantes desenvolveram outros projetos.

A experiência aqui descrita colaborou tanto para a preparação dos licenciandos como docentes, quanto para o próprio local em que estes estagiam. Contribuiu para a formação dos licenciandos porque, além de permitir integrar conhecimentos específicos e pedagógicos no contexto da prática educativa, favoreceu a autonomia e a reflexão necessária à formação docente; a escola, por sua vez, pôde ser auxiliada com novas metodologias e troca de saberes entre licenciandos e professores com experiências sobre a docência. A referida Licenciatura tem atuado na escola em projetos relacionados à sustentabilidade, colaborando nesse aspecto com novas práticas pedagógicas e discussões relacionadas ao tema com as professoras do Centro.

Nas três disciplinas envolvidas requisita-se um projeto de estágio sucinto a ser elaborado e desenvolvido pelo licenciando após acordos com a escola e orientações dos docentes responsáveis. Ao final, solicita-se um relatório das atividades realizadas, exigido para avaliação. As disciplinas foram: Metodologia do Ensino em Ciências Agrárias I, Instrumentação para o Ensino de Ciências Agrárias e Estágio Curricular em Licenciatura ${ }^{1}$. $\mathrm{O}$ trabalho realizado objetivou que os discentes desenvolvessem a prática de ensino específica em Ciências Agrárias em uma sequência didática de três aulas (atendendo requisitos da Metodologia do Ensino em Ciências Agrárias I), que utilizasse instrumentos didáticos construídos pelos próprios licenciandos, respeitando o contexto escolar vivenciado (atendendo requisitos da Instrumentação para o Ensino de Ciências Agrárias). Propiciou também ações de interação entre escola e comunidade, vivenciadas em uma situação real de ensino, e discussões sobre a continuidade do projeto na escola (atendendo aos requisitos do Estágio Curricular em Licenciatura).

A disciplina Metodologia do Ensino em Ciências Agrárias I fornece o amparo teóricometodológico para que o licenciando elabore metodologicamente a sua própria prática, com a necessidade de propor e desenvolver um projeto educativo com regência de aulas e supervisão na escola. O docente realiza a orientação da prática de ensino, acompanhando desde a inserção do estagiário na escola e o planejamento das aulas até a discussão das ações no estágio de acordo com o contexto escolar, de modo a favorecer a reflexão necessária ao aprimoramento.

A disciplina Instrumentação para o Ensino de Ciências Agrárias tem por objetivo apoiar e incentivar o desenvolvimento de materiais didáticos que facilitem o ensino das técnicas agrícolas e conteúdos da área das ciências agrárias, valorizando questões ambientais e sociais. A instrumentalização do educador deve ocorrer de forma teórica e, principalmente, prática, por meio do processo de elaboração, planejamento e avaliação de experimentos e recursos didáticos, como jogos direcionados para a educação em Ciências Agrárias.

A disciplina Estágio Curricular em Licenciatura tem como objetivo o contato dos alunos com diferentes realidades educacionais para identificar e problematizar aspectos relacionados aos conteúdos curriculares das disciplinas da formação pedagógica, bem como para realizar trabalhos de pesquisa, desde que ancorada na vivência na escola.

Nesse contexto, o diálogo entre as disciplinas apresentadas, respeitando-se as suas particularidades, justifica-se como o pano de fundo para consolidar a formação docente do licenciando. 


\section{Educação Infantil e o Trabalho com Abe- Ihas Jataís}

A Educação Infantil constitui a primeira etapa da educação básica no processo educativo conforme a LDB, Lei de Diretrizes e Bases da Educação Nacional (BRASIL, 1996). Nessa etapa, a escola colabora no processo de socialização, formação e desenvolvimento integral da criança. $\mathrm{O}$ objetivo da Educação Infantil, segundo o documento das Diretrizes Curriculares Nacionais Gerais da Educação Básica (BRASIL, 2013), é o desenvolvimento integral da criança até os seus cinco anos, em seus aspectos físico, afetivo, psicológico, intelectual e social, de modo a complementar a ação da família e da comunidade.

Essas Diretrizes Curriculares (BRASIL, 2013) propõem uma formação integral, enfatizando que as crianças necessitam brincar em espaços como pátios e jardins, com oportunidade de viver experiências de semear, plantar e colher os frutos da terra, e valorizando processos de construção de relação de identidade, reverência e respeito para com a natureza. Sob esse contexto, pode-se considerar a importância de atividades que adicionem prazer e participação em espaços naturais, de modo que elas tenham sua curiosidade instigada e interesse pelo aprendizado sobre meio ambiente. Ao ter contato com diferentes elementos, fenômenos e acontecimentos do mundo, sugere-se que as crianças sejam instigadas por questões significativas para observá-los e explicá-los (BRASIL, 1998).

Para que a experimentação e a diversificação de experiências ocorram, além do preparo de atividades com o apoio de recursos diferenciados, os professores podem buscar uma abordagem pedagógica que valorize as descobertas e possibilitem novas visões de mundo do estudante. Nesse sentido, existe a necessidade de desenvolver metodologias de ensino relacionadas às ciências naturais e agrárias ajustadas a uma perspectiva de educação ambiental para a educação infantil. Porém, elaborar novas formas de ensinar e aprender conceitos e questões da área em práticas pedagógicas de estágio tem significado diante do reconhecimento, pelos licenciandos e professores, das necessidades dessa faixa etária e da realidade escolar brasileira.

O tema escolhido foi a importância ecológica, especialmente para o processo de polinização, das abelhas sem ferrão nativas, bem como a diferenciação entre espécies inofensivas e potencialmente agressivas. A "espécie-modelo" escolhida foi a abelha jataí (Tetragonisca angustula).

Apesar de não serem as mais populares no país, o Brasil possui mais de quatrocentas espécies de abelhas nativas que pertencem à subfamília Meliponinae, e apresentam grande heterogeneidade de cor, tamanho, forma, hábitos de nidificação e população dos ninhos (PEREIRA, s/d). Esses insetos se caracterizam por serem espécies eussociais (vivem em colônias organizadas em castas sociais) e por possuírem o ferrão atrofiado, o que as impossibilita de usá-lo como defesa. Os meliponíneos são encontrados nas regiões tropicais e subtropicais do planeta, ocorrendo em toda a extensão do território nacional, embora as espécies difiram ao longo do país. Esse grande número de espécies pode ser explicado principalmente pelo processo de enxameação que o grupo apresenta, que contribui para o isolamento genético de populações próximas (FREITAS, 2003).

As "abelhas sem ferrão" possuem uma importância ecológica muito grande, pois, conforme o local onde vivem, são as responsáveis por $40 \%$ a 90\% da polinização das árvores nativas, sendo animais-chave para a formação e a perpetuidade das florestas (CARVALHO-ZILSE et al., 2007).

A jataí (Tetragonisca angustula) é uma dessas espécies de "abelhas sem ferrão", pertencente à Tribo Trigonini. Também chamada popularmente de abelha-ouro, jati, três-portas ou abelha de botas, apresenta cabeça e tórax pretos, abdômen escuro a dourado e pernas amarelas a douradas. Mede até quatro milímetros de comprimento e possui ampla distribuição no território do Brasil. As jataís, assim como muitas espécies de abelhas sem ferrão, constroem seus ninhos em cavidades de árvores. Em ambientes que sofreram ação antrópica, nidificam em buracos e fendas de paredes, muros, calçadas e lajes (FREITAS, 2003). Essas abelhas apresentam comportamento pacífico e não representam 
riscos para a integridade física, o que permite a crianças interagirem com elas em aulas práticas, por exemplo.

\section{A Construção de Conhecimentos dos Estudantes da Licenciatura na Elaboração de Instrumentos de Ensino e Realização do Estágio}

A primeira etapa deste projeto foi a realização de reuniões com a equipe de professoras e direção do CCIn, para discutir o interesse em projetos sobre sustentabilidade na educação infantil com a colaboração da unidade. Esses projetos envolvem a participação de graduandos, coordenados pelas docentes da área de Licenciatura e têm como objetivo a aprendizagem da docência. Após o acordo, iniciaram-se os projetos dos alunos no local. Em aulas das disciplinas mencionadas, houve a definição, pelos licenciandos, do tema a ser trabalhado, aspecto discutido e orientado nas aulas referentes à disciplina de Instrumentação. A escolha do assunto "abelhas e polinização" se deu por afinidade pessoal dos graduandos e pelo fato de que o CCIn, local do estágio, oferece e valoriza o contato das crianças com a natureza, através de diversas práticas e rotinas realizadas ao ar livre, entre outros fatores.

Considerando a curiosidade infantil e a ocorrência de abelhas nos jardins, ensiná-los sobre esses insetos e a sua importância para o meio ambiente era trabalhar um tema muito próximo da realidade das crianças. Além disso, é um tema que permite trabalhar uma perspectiva de educação ambiental ao enfatizar a convivência das crianças com as abelhas e buscar minimizar o distanciamento ser humano-natureza.

A partir disso, os estudantes de Licenciatura, orientados pelas docentes autoras deste trabalho, puderam planejar, discutir com as orientadoras e com professoras da escola como o projeto seria desenvolvido no semestre. Vale ressaltar que, antes que as atividades práticas tivessem início, foi elaborado um termo de concordância, apresentado aos pais e/ou responsáveis pelas crianças em uma reunião no CGIn, na qual o projeto foi explicado e as dúvidas esclarecidas. Todos os responsáveis legais concordaram com a realização das etapas do trabalho. Atividades de planejamento e esclarecimentos aos pais colaboraram para dirimir dúvidas e diminuir o temor de picadas nas crianças em contato com as abelhas.

Após o início da vivência na escola pelos licenciandos, a primeira etapa foi a confecção, em madeira, de uma caixa-ninho de abelhas jataís, a ser utilizada como instrumento de ensino. Inicialmente, estudou-se com as professoras da educação infantil onde poderia ser colocada a caixa-ninho, considerando seu tamanho, forma e facilidade de alcance. A seguir foi iniciada a esquematização da construção, baseada em recomendações técnicas especializadas (VENTURIERI, 2008), buscadas pelos licenciandos antes de sua execução (Figura 1).

Essa forma de criação das abelhas em caixaninho não é prejudicial aos insetos, pois reproduz artificialmente as condições naturais de estrutura e a organização social das abelhas. As caixas-ninhos de madeira, já utilizadas em criações comerciais, são modulares e possibilitam o monitoramento da colmeia sem destruir a sua estrutura - tornando-se, então, interessantes instrumentos de ensino. Respeitar a estrutura e modo de vida das abelhas e discutir esse aspecto com as crianças apoiam a proposta de relacionar o trabalho à educação ambiental.

A caixa foi feita em madeira, sendo que a Esalq conta com marcenaria no Laboratório de Movelaria e Resíduos Florestais, que auxiliou na construção e tem atuado no apoio ao curso de Engenharia Florestal (Figura 2).

Com a caixa-ninho pronta, foram realizadas a captura pelos próprios graduandos e a criação de um enxame de abelhas jataís e, seguindo recomendações técnicas, houve necessidade de capturar a rainha. Todo o processo de construção da caixa-ninho, bem como de captura, manejo e instalação na escola, foi registrado pelos licenciandos conforme orientação da docente da disciplina Instrumentação para o ensino de Ciências Agrárias, a fim de poder auxiliar futuros trabalhos. Cabe indicar que, na área de Ciências Agrárias, os materiais pron- 


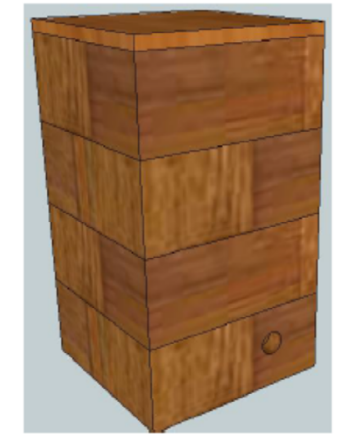

Perspectiva geral da caixa-ninho, com seus quatro componentes (ninho, sobre-ninho e duas melgueiras) mais a tampa

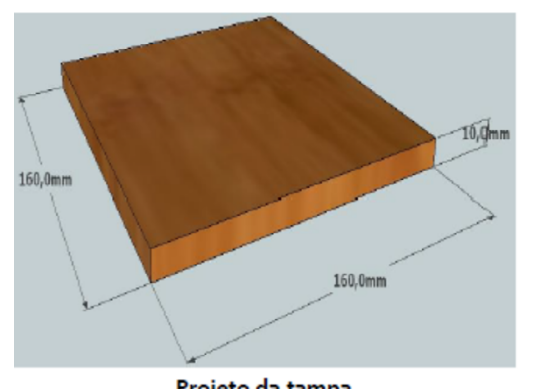

Projeto da tampa
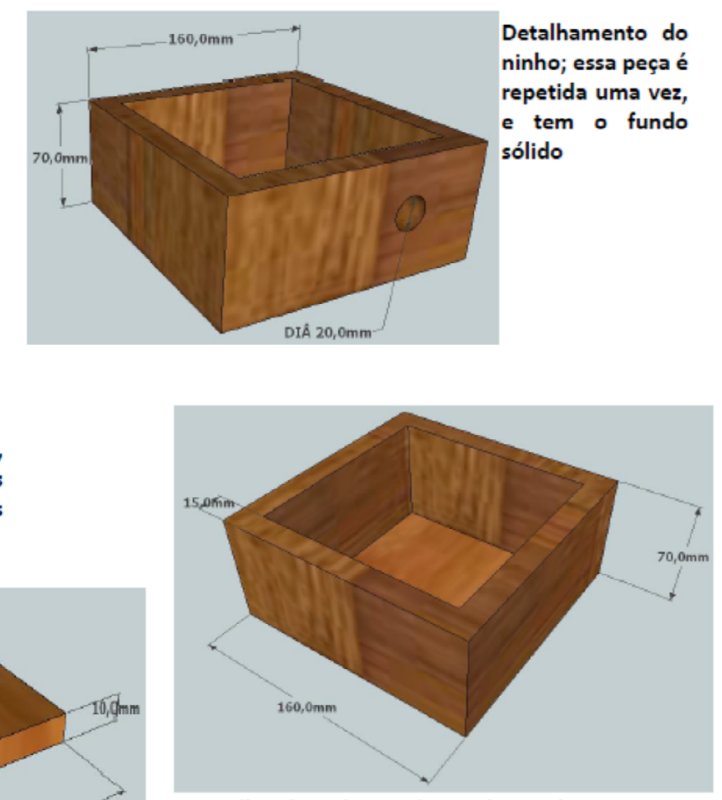

Detalhe do sobre-ninho e das melgueiras; essa peça será construída três vezes, com dois fundos diferentes (uma peça com o fundo de losango e as outras duas com o fundo ripado)

Desenho dos fundos das caixas: o ninho será sólido, o sobre-ninho com o losango e as duas

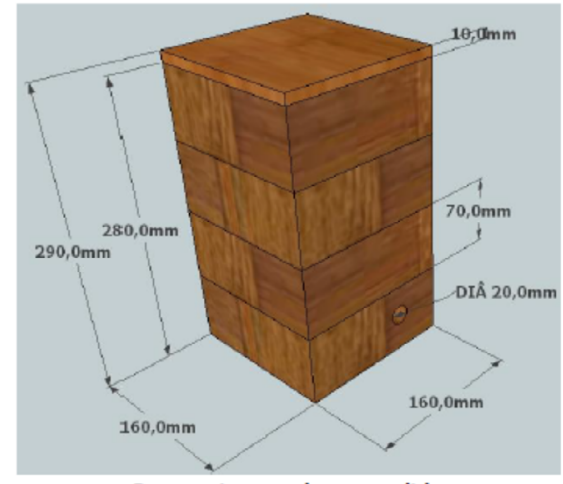

Perspectiva geral com medidas

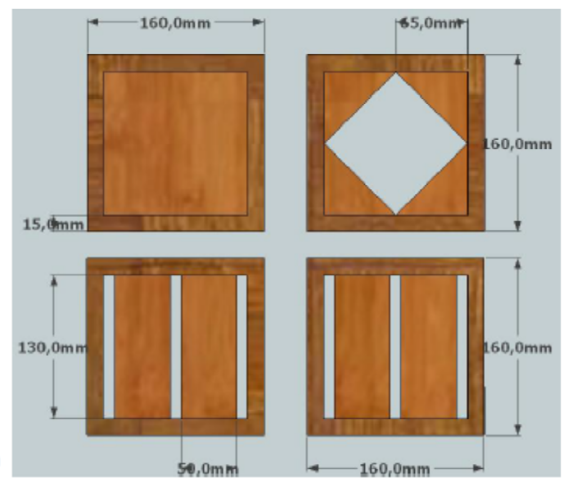

melgueiras com as ripas

Figura 1 - Desenho técnico da caixa-ninho elaborada pelos licenciandos. Fonte: Próprios autores.

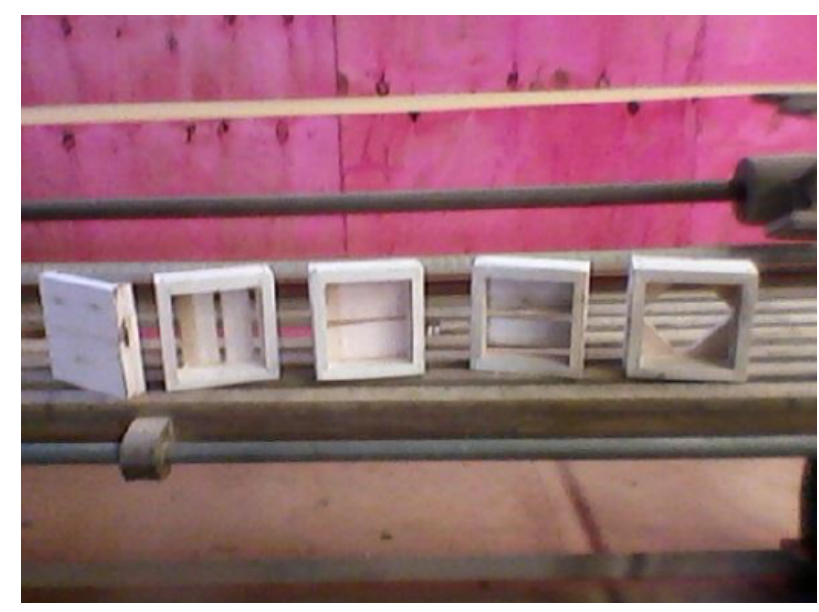

(a)

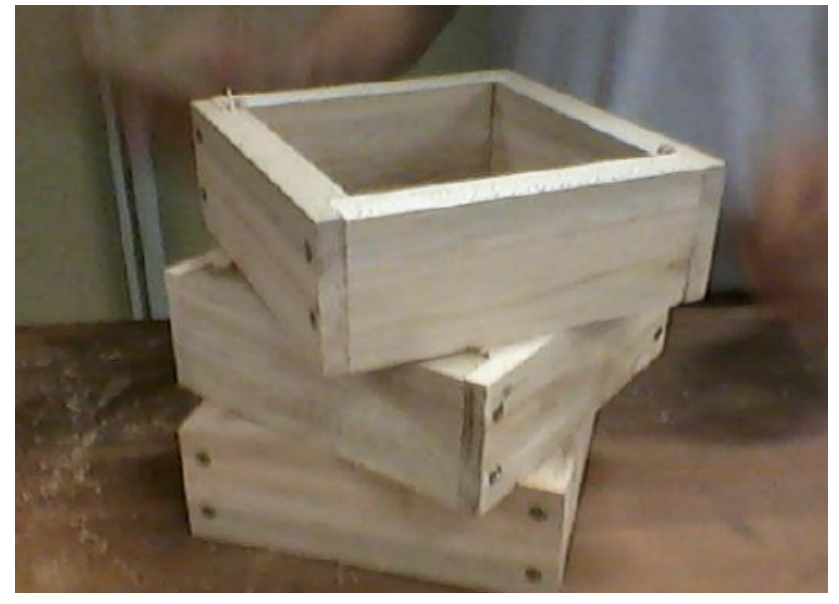

(b)

Figura 2 - (a) Compartimentos da caixa-ninho de abelhas jataís. (b) Montagem das melgueiras. Fonte: Próprios autores.

tos e disponíveis para aquisição, eventualmente instrumentos de ensino, dificilmente se destinam aos alunos dos níveis iniciais de ensino. Também parecem faltar instrumentos e recursos para a área na educação profissional, enquanto na escola de nível fundamental e médio muitas disciplinas contam com recursos específicos, como os livros didáticos. Esses aspectos justificam a preocupação com o preparo de futuros professores capazes de atuar na elaboração de recursos na área.

Durante o período de estágio sob a supervisão da professora responsável na escola, os licenciandos se dedicaram a observações do dia a dia da turma, que visaram a estabelecer o contato entre os acadêmicos e as crianças e propiciar reflexões sobre as formas de ensino e necessidades dos alunos 
dessa idade. Essa atividade integra a proposta de estágio de observação e participação, que necessita deixar de ser ação passiva e de imitação do que é feito, como tem sido relatado (PIMENTA, 2004), para tornar-se oportunidade de aprendizado. Conforme os relatos e descrições dos licenciandos, registrados em relatório da disciplina Metodologia de Ensino em Ciências Agrárias I, essa fase de observação e participação revelou-se essencial para reconhecimentos, pelos estagiários, da dinâmica da escola e das necessidades dos alunos, colaborando no planejamento da metodologia das três aulas, que compõe o projeto relativo à disciplina de Metodologia de Ensino em Ciências Agrárias I. As horas referentes ao cumprimento de estágios nas diferentes disciplinas foram respeitadas e assinada a presença dos licenciandos na escola.

A sequência didática foi desenvolvida desta forma:

a)Aula 1: Introdução do projeto pelos licenciandos. Solicitou-se que as crianças desenhassem abelhas e insetos. Identificaram-se os desenhos, bem como foram questionadas e anotadas as partes do corpo das abelhas, conforme descrição das próprias crianças. Na sequência, fez-se uma roda de conversa, apresentando conceitos sobre insetos, abelhas e o processo de polinização. Foram mostradas imagens reais de abelhas sem ferrão e abelhas (ou vespas) potencialmente agressivas. b) Aula 2: Retomado o tema da polinização, desenvolveu-se uma atividade preparada pelos licenciandos e orientada nas aulas na universidade. $\mathrm{Na}$ atividade, as crianças deveriam conduzir um boneco de abelha até uma flor, a qual serviu de apoio para o ensino. Apresentaram-se materiais técnicos apícolas (cera, quadros e mel), para explicar a existência de formas de interagir com as abelhas com finalidade produtiva.

c) Aula 3: Mostrou-se a caixa-ninho com as abelhas, que foi aberta para as crianças observarem os insetos vivos e sua organização social. Elas fizeram perguntas e tiveram acesso a uma lupa para observarem a morfologia dos insetos. Ao final da atividade, foi solicitado novamente que desenhassem abelhas.

\section{Aprendizagens na Graduação com Propos- ta de Estágio Integrado}

Destacam-se três aspectos para os quais este trabalho contribuiu: a) para a experiência dos licenciandos como docentes, ao projetarem e conduzirem a intervenção pedagógica incluindo um instrumento de ensino e sua confecção; b) para o diálogo entre as disciplinas da Licenciatura em uma proposta de estágio integrado, em que eles atuaram como articuladores; c) para a reflexão sobre a aprendizagem das crianças no tema escolhido, as abelhas jataís e sua forma de vida.

A concepção e o desenvolvimento do projeto foram desafiadores para os licenciandos ao demandar a adequação da metodologia de ensino de um conteúdo técnico da área de Ciências Agrárias como é a criação de abelhas, considerando as diretrizes e referenciais da educação infantil. Houve necessidade de busca teórica dos licenciandos, os quais estudaram essas orientações ao proporem as aulas.

Notou-se a preocupação deles em trabalhar de forma que o assunto fosse atrativo e que as crianças pudessem compreender e interagir com o instrumento proposto - a caixa de abelhas jataís. $\mathrm{Na}$ tentativa de desenvolver uma "abordagem didática" para a educação infantil, os graduandos atentaram para a fase de desenvolvimento cognitivo de crianças da faixa etária em que estagiavam.

Segundo o relato dos licenciandos, o ambiente da sala de aula era complexo em função das percepções distintas entre os alunos e de as "aulas" serem conduzidas na forma de conversas breves, com todos os alunos. Para os licenciados, foi um aprendizado lidar com perguntas e comentários inusitados das crianças, que não raro exigiam que se autoquestionassem e buscassem explicações que respondessem às perguntas, mas fossem inteligíveis para as crianças.

Desse modo, a preocupação com a linguagem e com a possibilidade de o aluno agir sobre o objeto concreto foi relacionada com os conhecimentos sobre o desenvolvimento cognitivo aprendidos em disciplinas de graduação. Para estabelecer essas articulações, os conhecimentos foram lembrados e 
contextualizados nas reuniões de orientação entre docentes da universidade e licenciandos, favorecendo a relação teoria e prática no curso. Também aprenderam sobre as necessidades de cuidado e rotinas na educação infantil, especialmente pela colaboração com as professoras da escola.

Os licenciandos notaram a importância do planejamento das aulas, bem como da revisão desse plano após as observações iniciais da turma, a fim de adequar o processo às demandas da classe, sem deixar de abordar os tópicos selecionados como essenciais. Os graduandos puderam elaborar a própria prática, na medida em que se propuseram a pensar nos aspectos pedagógicos e técnicos, no que se refere à construção da caixa-ninho de abelhas, e em suas necessidades para conseguirem conduzir as atividades com crianças pequenas. $\mathrm{O}$ investimento na capacidade de elaboração da própria prática é relevante na autonomia dos professores e na capacidade de propor e compromissar-se com essa prática.

Além disso, a elaboração e a confecção da caixa-ninho, entendida aqui como instrumento de ensino, permitiram a interação das crianças com as abelhas quando esta foi levada à sala. $\mathrm{O}$ ninho foi colocado no jardim da escola. A confecção da caixa necessitou estudos prévios de técnicas recomendadas para a criação de abelhas sem ferrão, articulando a aprendizagem de conhecimentos específicos, conceituais e procedimentais (ZABALA, 1998) ao trabalho a ser desenvolvido no estágio. Couberam aos estagiários reflexões sobre as possibilidades didáticas de uso da caixa.

Os estudantes da Licenciatura também apresentaram como experiências marcantes as diferentes situações espontâneas no momento da aula, e que tinham de ser conduzidas para que não atrapalhassem o desenvolvimento das atividades. Em particular, considerando a faixa etária das crianças, uma das maiores dificuldades encontradas foi a rápida distração dos alunos, às vezes sem "grandes motivos", mas que exigia esforços no sentido de "prender novamente a atenção da criança", segundo os licenciandos.

Mas como avaliar a aprendizagem de crianças na educação infantil? Como saber se estão aprendendo? Uma alternativa discutida em orientações e escolhida pelos licenciandos foi coletar os desenhos dos alunos e analisá-los, questionando a criança sobre os registros e, nesta ação, percebendo avanços e complexidades nos desenhos. Optouse por solicitar desenhos de abelhas no início, de modo a sondar os conhecimentos prévios, e ao final das regências dos licenciandos. $\mathrm{O}$ desenho também foi uma forma de contar com um registro escrito dos alunos e de possibilitar um momento lúdico em aula.

Assim, considerando o ponto de vista das crianças, a Figura 3 representa os desenhos feitos antes de qualquer atividade (momento inicial do trabalho), e a Figura 4 refere-se aos desenhos realizados após todas as atividades.

É marcante a diferença nos desenhos das crianças quanto às abelhas: nos primeiros, nota-se que todas são semelhantes e apresentam um ferrão bem marcado; outros órgãos também comuns nas representações são as antenas e as asas.

Os desenhos feitos após todas as atividades apresentaram uma nova visão dos insetos: apenas uma criança desenhou ferrão na abelha, porém a associou a uma colmeia diferente da caixa-ninho levada na última intervenção. Todas as outras abelhas desenhadas não tinham ferrão, e estavam sempre relacionadas com um ninho quadrado e com divisões internas, semelhante ao que foi mostrado na prática. Uma criança chegou até a desenhar os potes de cera que foram vistos dentro da caixaninho quando aberta. Possivelmente, entenderam que nem toda abelha tem ferrão e relacionaram o desenho às jataís, desmistificando a ênfase no lado negativo das abelhas dos desenhos iniciais (picam, ferroam e fazem mal).

As crianças puderam ver a morfologia das abelhas com o auxílio de lupas. Não foi dada ênfase à descrição das partes dos insetos, priorizou-se a curiosidade. Os licenciandos perceberam como essa atividade de solicitar o desenho antes e depois das atividades se mostrou interessante para entender como o aluno aprende. Segundo os estagiários, foi notável identificar que a criança 

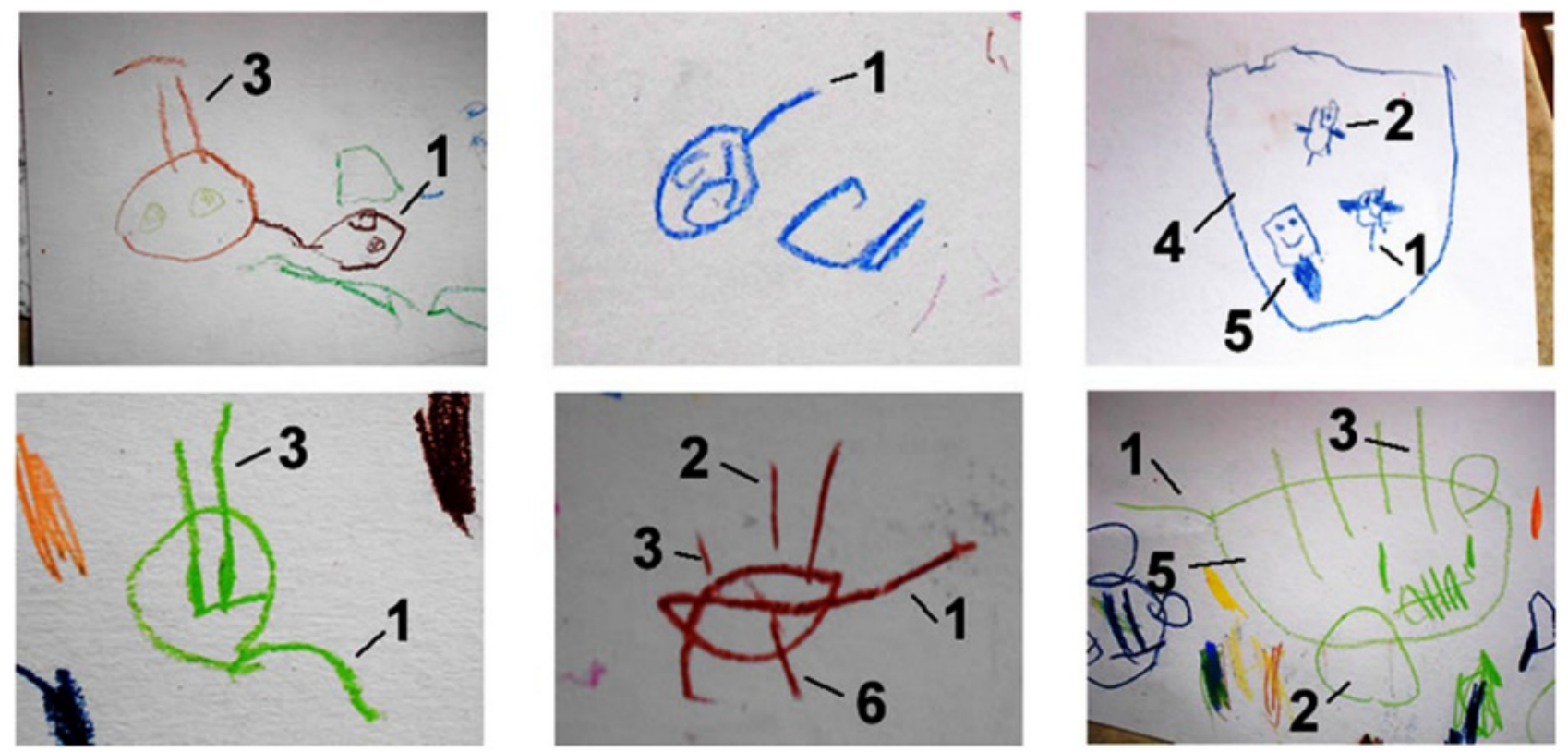

Figura 3 - Seleção de alguns dos trabalhos realizados na primeira atividade de estágio dos licenciandos em Ciências Agrárias. Conforme interpretação dos desenhos feita pelas próprias crianças, foram representados: ferrão (1), asas (2), antenas (3), colmeia (4), abelha-rainha (5) e pernas (6).
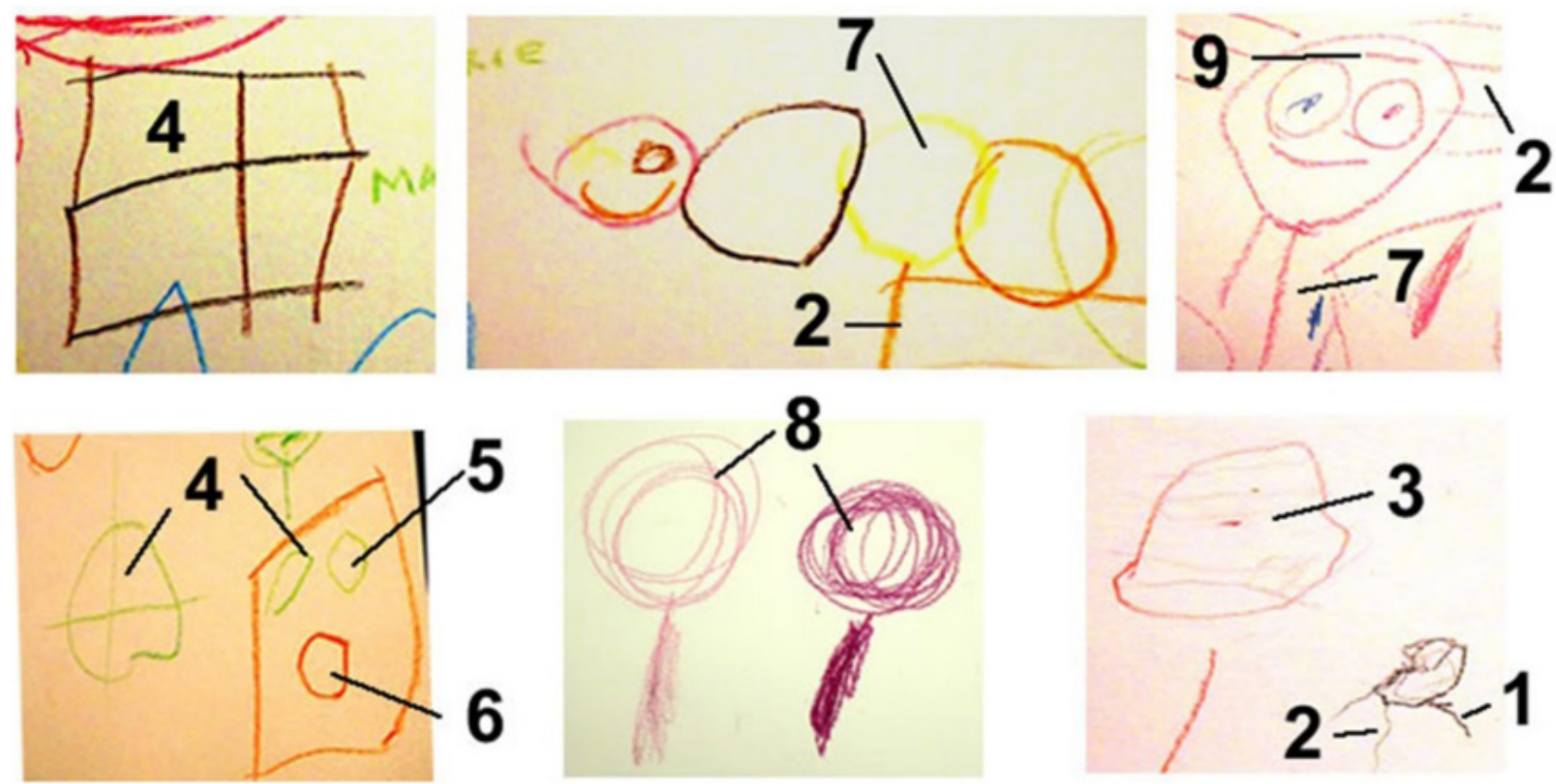

Figura 4 - Seleção de seis desenhos elaborados pelas crianças na última atividade de estágio dos licenciandos em Ciências Agrárias. Conforme interpretação dos desenhos feita pelas próprias crianças, foram representados: ferrão da "abelha que pica" (1), asas (2), colmeia da "abelha que pica" (3), "caixinha da abelha que não pica", com divisões internas (4), cera (5), potes de mel (6), corpo segmentado das abelhas (7) (notar que não foi desenhado o ferrão), lupa utilizada na observação (8) e antenas (9).

percebeu detalhes não explicados: por exemplo, um desenho tem uma abelha sem ferrão e com o corpo segmentado - como de fato é o inseto. Os licenciandos entenderam que essa representação só foi possibilitada porque a criança utilizou anterior- mente a lupa - e, para eles, esse instrumento teve tal aceitação, que também foi desenhado.

A variedade de itens desenhados e a representação de dois tipos de abelha, as que picam e as que não picam, demonstram assimilação do 
conhecimento pelas crianças, indicando aos licenciandos que o trabalho foi efetivo.

A visão das professoras da turma, registrada através de relatos nos diários das conversas na escola, foi positiva: ambas as professoras disseram ser possível utilizar a caixa-ninho de jataís como um instrumento em sala de aula, e afirmaram serem perceptíveis a aprendizagem e o interesse das crianças em relação ao tema.

Em relação à receptividade do trabalho pelas professoras da escola, perceberam-se a aceitação e a abertura, uma vez que as docentes responsáveis se mostraram interessadas na forma como os estagiários iriam abordar o assunto "abelhas e polinização" com as crianças. Ao final, as professoras consideraram interessante a metodologia utilizada e, principalmente, ter colocado as crianças em contato direto com as abelhas através da caixa-ninho de jataís. Uma das professoras recebeu o registro dos licenciandos sobre a forma de elaboração da caixa-ninho, para que a escola possa aproveitar as informações. Muitos pais, estudantes de pós-graduação da unidade, indicaram satisfação com as "novidades" que os alunos traziam para casa durante o período, pois muitos tinham afinidade com o tema e puderam dialogar com as crianças.

A aprendizagem da docência pelos dois alunos de Licenciatura foi avaliada por meio de discussões com os docentes autores deste trabalho e de apresentações de relatórios de estágio. Conforme constatado nos relatórios, foi consenso entre os licenciandos que o estágio, da forma como desenvolvido, significou oportunidade de estabelecer a relação entre os conceitos aprendidos durante o curso da Licenciatura e a possibilidade de fazerem sentido na prática - desde o momento da definição da metodologia, adequando os conceitos à fase de desenvolvimento cognitivo das crianças, até a escrita dos registros e relatórios, que demandam organização, síntese e reflexão sobre uma vivência.

\section{Considerações Finais}

A integração das disciplinas do curso de Licenciatura, cada qual com o seu foco e suas exi- gências em particular, decorreu da proposta de estágio integrado.

Essa integração possibilitou uma vivência mais completa e compromissada com a atividade docente, proporcionando uma visão mais abrangente da prática docente e uma formação para a autonomia que requer criar, propor e analisar ações. Conforme os relatórios entregues nas disciplinas e também reuniões de orientação, a experiência foi diferenciada para os licenciandos principalmente pelo fato de exigir que estes participassem de todas as etapas da intervenção pedagógica, desde a idealização da atividade com abelhas sem ferrão, o contato com o CCIn e com as professoras supervisoras, a confecção do instrumento, além do desafio de ensinar crianças pequenas.

A necessidade de adequar um conteúdo ao ensino de crianças de três a quatro anos que incluísse a criação e o manejo das abelhas exigiu estudar e pensar diferentes possibilidades de metodologias, de instrumentos pedagógicos e de interação com as crianças. Dessa forma, segundo afirmação dos próprios licenciandos, diferentes conhecimentos da Licenciatura - como a Psicologia e a Didática - e do curso de origem (a Engenharia Florestal) foram mobilizados a fim de tornar o projeto coerente, minimizando os impactos da fragmentação disciplinar na formação do estudante.

A interdisciplinaridade do trabalho, intrínseca em todas as etapas, demandou o alinhamento da proposta de orientação para a prática. Nesse sentido, o suporte às ações bem como a concepção que nortearia o trabalho de estágio envolveram três enfoques, embora na situação real houvesse pouca delimitação entre os resultados de cada uma das disciplinas envolvidas. Uma disciplina priorizou a discussão do instrumento como fomento à prática, a outra priorizou a regência e a construção da identidade docente, e a terceira, a relação com os pais e professoras e a elaboração de registros do processo, além dos relatórios. Segundo tais relatórios, as três disciplinas foram fundamentais para tornar a experiência significativa, pois exigiram dos licenciandos os trabalhos de "idealizar - construir - realizar refletir - reformular", fechando assim o "ciclo" de 
um projeto. $\mathrm{O}$ caminho para fechar esse ciclo não foi linear, pois os licenciandos constantemente se questionaram, discutiram e solicitaram orientações, como requer um processo complexo, mas que pode ser fascinante, de tornar-se professor.

\section{Agradecimentos}

Os autores agradecem ao Laboratório de Movelaria e Resíduos Florestais, do Departamento de Ciências Florestais, sob a coordenação da Profa. Dra. Adriana Maria Nolasco, ao Sidney Antonio Theodoro, técnico do laboratório de movelaria, que ajudou na confecção das caixas-ninho; à Sandra de Fátima Cruz, diretora do Centro de Convivência Infantil "Ermelinda Ottoni de Souza Queiroz" (CCIn), assim como a todas as professoras e aos funcionários do CCIn pela parceria, colaboração e incentivo às atividades pedagógicas da Esalq.

\section{Nota}

1 Disciplina atualmente denominada Estágio Curricular em Licenciatura: Teoria e Prática. A realização dos estágios da Licenciatura em Ciências Agrárias prioriza a vivência em escolas profissionais de Ensino Médio, sendo os estágios na educação infantil eventuais. Porém, como as escolas de educação profissional nas áreas de Agropecuária, Meio Ambiente e afins são raras na região, abre-se exceção. Cabe pensar em novas oportunidades profissionais para os formados na Licenciatura em Ciências Agrárias como docentes de apoio às práticas pedagógicas que envolvam a construção de hortas, jardins e ações agroecológicas e sustentáveis nas escolas de educação infantil.

\section{Referências Bibliográficas}

BRASIL. Referencial Curricular para a Educação Infantil. Brasília: Ministério da Educação, $3^{\circ}$ vol., 1998.

BRASIL. Lei de Diretrizes e Bases da Educação Nacional. Lei número 9394, 20 de dezembro de 1996.
BRASIL. Diretrizes Curriculares para a Educação Infantil. Brasília. Ministério da Educação, 2013.

CARVALHO-ZILSE, G. A. et al. Criação de Abelhas sem Ferrão. Coleção Iniciativas Promissoras, vol. 2. Programa Pró-Várzea. Manaus: Instituto Nacional de Pesquisas da Amazônia (INPA), 2007. 18 p.

GUNHA, M. I. "Inovações Pedagógicas: o Desafio da Reconfiguração de Saberes na Docência Universitária". Cadernos de Pedagogia Universitária da Universidade de São Paulo (USP). USP, Pró-Reitoria de Graduação, 2008, pp. 1-38.

DIAS-DA-SILVA, M. H. G. F. \& MUZZETI, L. R. "Licenciaturas Ligth: Resultado das Lutas Concorrenciais no Campo Universitário?". Contexto \& Educação. Ijuí, ano 21, n. 75, pp. 11-28, 2006.

ESCOLA SUPERIOR DE AGRICULTURA LUIZ DE QUEIRÓZ (ESALQ). Projeto Político-Pedagógico da Licenciatura em Ciências Agrárias. 2015. Disponível em: <http://www4.esalq.usp.br/graduacao/cursos/licenciatura $>$. Acessado em 2 nov. 2017.

FLORES, M. A. "Formação e Identidade Profissional: Resultados de um Estudo Longitudinal". In: MOREIRA, A. F. B.; ALVES, M. P. C. \& GARCIA, R. L. (orgs.). Currículo, Cotidiano e Tecnologias. Araraquara:JM Editora, 2006.

FREITAS, B. M. Meliponineos: a Vida das Abelhas. CD-ROM. Fortaleza: Universidade Estadual do Ceará, 2003.9 p.

MASSABNI, V. G. Os Conflitos de Licenciandos e o Desenvolvimento Profissional Docente. Educação e Pesquisa. São Paulo, vol. 37, n. 4, pp. 793-808, 2011.

PEREIRA, F. M. "Abelhas sem Ferrão, a Importância da Preservação". Embrapa Meio-Norte. Disponível em: <http://www.cpamn.embrapa.br/apicultura/abelhasSemFerrao.php>. Acessado em 7 mar. 2014.

PIMENTA, S. G. O Estágio na Formacão de Professores: Unidade, Teoria e Prática? $6^{\mathrm{a}}$ ed. São Paulo: Cortez, 2015.

TARDIF, M. Saberes Docentes e Formaşão Profissional. Petrópolis, RJ: Vozes, 2002.

VENTURIERI, G. C. Criaşão de Abelhas Indígenas sem Ferrão. 2 ed. Belém: Embrapa Amazônia Oriental, 2008, 60p.

ZABALA, A. A Prática Educativa: Como Ensinar. Porto Alegre: Artmed, 1998. 